\title{
Effect of process parameters and grain refinement on hot tearing susceptibility of high strength aluminum alloy 2139 in laser powder bed fusion
}

\author{
Joe Elambasseril ${ }^{1} \cdot$ Michael J. Benoit $^{2} \cdot$ Suming Zhu ${ }^{1} \cdot$ Mark A. Easton $^{1}$ (1) $\cdot$ Edward Lui ${ }^{1} \cdot$ Craig A. Brice $^{3} \cdot$ Ma Qian $^{1}$. \\ Milan Brandt ${ }^{1}$
}

Received: 14 July 2021 / Accepted: 26 December 2021 / Published online: 19 February 2022

(c) The Author(s) 2022

\begin{abstract}
High strength aluminum alloys, especially those that are age-hardenable, such as 2xxx series, 6xxx series, and 7xxx series, are widely used as structural materials in transport and aerospace industries due to their good mechanical properties. However, additive manufacturing of high strength aluminum alloys is challenging due to their susceptibility to hot tearing. In this work, a systematic study has been conducted in an attempt to eliminate hot tearing in laser powder bed fusion (PBF-LB/M) manufacturing of Al2139 alloy through selecting process parameters and the addition of an AlTiB grain refiner. It was found that hot tearing in Al2139 during PBF-LB/M can be reduced or eliminated by increasing volumetric energy density. Furthermore, grain refinement by AlTiB addition shows a clear effect in reducing hot tearing, even though the refined grains remain predominantly columnar rather than equiaxed. The effect of increasing volumetric energy density on hot tearing of Al2139 during PBF-LB/M was analyzed by thermomechanical finite-element simulation, which showed that the reduction in hot tearing with increasing energy density is associated with a decrease in the thermal residual stress. However, it was also shown that there can be a substantive loss of $\mathrm{Mg}$ due to evaporation at high energy densities. From a hot tearing model based on solidification thermodynamics, the loss of $\mathrm{Mg}$ on hot tearing in Al2139 was estimated to reduce hot tearing by up to $10 \%$, compared to the initial powder composition. With the selected PBF-LB/M parameters, crack-free tensile specimens were fabricated, with and without the addition of AITiB. Compared with their wrought or cast counterparts, the PBF-LB/M Al2139 and Al2139-AlTiB specimens show lower yield strength but better ductility, which can be attributed to the loss of Mg during PBF-LB/M.
\end{abstract}

Keywords Additive manufacturing $\cdot$ Laser powder bed fusion · Selective laser melting · Aluminum alloys · Hot tearing · Solidification cracking $\cdot$ Grain refinement

\section{Introduction}

Laser-based powder bed fusion of metals (PBF-LB/M), also referred to as selective laser melting (SLM), is a premier metal additive manufacturing (AM) method for the fabri-

Mark A. Easton

mark.easton@rmit.edu.au

Milan Brandt

milan.brandt@rmit.edu.au

1 Centre for Additive Manufacturing, School of Engineering, RMIT University, Melbourne, VIC 3001, Australia

2 School of Engineering, University of British Columbia, Kelowna, BC V1V 1V7, Canada

3 Mechanical Engineering Department, Colorado School of Mines, Golden, CO 80401, USA cation of customized metal components. Along with stainless steels, titanium alloys, superalloys (nickel and cobaltchrome based), and copper alloys, additively manufactured aluminum (Al) alloys are finding increasing applications [1-3]. However, Al alloys present several challenges for AM. The sensitivity of Al to surface oxidation, the propensity to absorb hydrogen from moisture in the atmosphere, the possibility of powder blowing by gas flow in the PBF$\mathrm{LB} / \mathrm{M}$ chamber, and the poor flowability during layering make porosity a common issue for Al components [4]. 
Furthermore, the tenacious oxide film on the surface of $\mathrm{Al}$ powder particles can obstruct melting of powder particles and provides nucleation sites for defect formation [5-8]. Moreover, $\mathrm{Al}$ has high thermal conductivity and high reflectivity to laser wavelengths usually used in PBF-LB/M, which results in a relatively low melting efficiency. Although these deficiencies can be partially alleviated using a high laser power and an inert atmosphere, the use of a high laser power can have an undesirable effect of vaporizing critical strengthening elements with low boiling points (i.e., $\mathrm{Mg}$ and $\mathrm{Zn}$ ).

Another challenge for PBF-LB/M of high strength or precipitation hardenable $\mathrm{Al}$ alloys (i.e., $2 \mathrm{xxx}, 6 \mathrm{xxx}$, and $7 \mathrm{xxx}$ series) is their susceptibility to hot tear during the terminal stages of solidification when the alloys are in the mushy state, resulting in an impairment to the mechanical properties of the printed component [9]. In general, the hot tearing mitigation strategies developed for conventional casting and welding of high strength $\mathrm{Al}$ alloys have been adopted or adapted to reduce hot tearing during PBF-LB/M, which include process control, parameter optimization, and grain refinement.

Build plate pre-heating is a commonly used process control technique for mitigating hot tearing, by which the elevated temperature of the build plate reduces the thermal gradient in the printed material. Several studies have investigated build plate temperatures between 200 and $400{ }^{\circ} \mathrm{C}$ for PBF-LB/M of $2 \mathrm{xxx}$ alloys, but the success was limited as cracks still occurred even with pre-heating in some cases $[4,10,11]$. Process parameter optimization has largely focused on volumetric energy density (i.e., laser power, scan speed, hatch spacing, and layer thickness). For instance, it has been found that hot tearing in 2xxx alloys decreases with decreasing scan speed or increasing volumetric energy density [2,12-16]. The effect of other process parameters has received less attention, although the selection of hatch spacing appears to critically affect hot tearing $[14,16]$. However, there is a lack of consensus on the effect of process parameters on hot tearing in 2xxx alloys and how the hot tearing susceptibility is affected by process parameters remains to be explored.

A characteristic of the PBF-LB/M process which exacerbates hot tearing is the formation of coarse columnar grains, which often traverse multiple build layers due to epitaxial growth and large thermal gradients. Therefore, a promising route to mitigating hot tearing is through grain refinement, as fine equiaxed grains are known to reduce the propensity to hot tearing due to a lower coherency temperature, thinner liquid films, greater capillary pressure between grains, and the ability to rotate and deform to accommodate the thermally induced stress of parts $[17,18]$. The addition of scandium $(\mathrm{Sc})$ is a popular grain refinement strategy used for $\mathrm{AM}$ of $\mathrm{Al}$ alloys, where primary $\mathrm{Al}_{3} \mathrm{Sc}$ particles form in the melt pool to provide heterogeneous nucleation sites [19-21], although it has not been commonly used for PBF-LB/M of 2xxx alloys.
Moreover, the high cooling rates of the PBF-LB/M process allow for greater solid solubility of $\mathrm{Sc}$ in the $\mathrm{Al}$ matrix, providing enhanced precipitation hardening during subsequent heat treatment, which has been already demonstrated in electron beam melting of an Al-2Sc master alloy [22].

Significant grain refinement and hot tearing reduction during PBF-LB/M of 2xxx alloys have been achieved using zirconium $(\mathrm{Zr})$, which forms $\mathrm{Al}_{3} \mathrm{Zr}$ particles with $\mathrm{Al}$ in the melt pool as heterogeneous nucleation sites $[12,15]$. The use of $\mathrm{Zr}$ has further proven to be effective in eliminating hot tearing through grain refinement during PBF-LB/M of the crack susceptible 7075 alloy [23]. As reviewed recently [24], there have been a number of successful approaches to utilizing grain refinement for suppression of hot tearing during PBF$\mathrm{LB} / \mathrm{M}$ of $\mathrm{Al}$ alloys by adding a relatively large amount of nano-sized particles [25-28]. The use of commercially available AlTiB grain refiners has not been widely studied until recently, despite AlTiB appearing to have a stronger grain refining effect in rapidly solidified Al alloys than Sc [29]. Wang et al. [13] reported a reduction in the average grain size from 23 to $2.5 \mu \mathrm{m}$ for PBF-LB/M of an Al-3.5Cu-1.5 Mg alloy with an addition of $\mathrm{TiB}_{2}$ powder, which was, however, introduced as a reinforcing phase rather than as a master alloy. A similar reduction in grain size was reported by Jiang et al. [30] during laser directed energy deposition of a 7075/ $\mathrm{TiB}_{2}$ composite. More recently, $\mathrm{TiB}_{2}$ has been investigated as an intentional grain refiner in PBF-LB/M for 2xxx [31] and $7 \mathrm{xxx}$ [32] alloys, demonstrating effective grain refinement and hot tearing reduction in both cases.

The main objective of this study is to obtain crack-free A12139 by PBF-LB/M, with mechanical properties matching those of the wrought or cast counterparts. Al2139 is an $\mathrm{Al}-\mathrm{Cu}-\mathrm{Mg}-\mathrm{Ag}$ alloy with excellent mechanical properties and creep resistance at elevated temperature, due to the formation of the fine and uniformly distributed $\mathrm{Al}_{2} \mathrm{Cu}$ precipitates on the $\langle 111\rangle_{\alpha}$ planes [33]. In this paper, we show the elimination of hot tearing in PBF-LB/M of A12139 through parameter selection and grain refinement using a commercial Al5Ti1B grain refiner. Thermomechanical and thermodynamic simulations are used to assist the analysis of hot tearing susceptibility.

\section{Materials and methods}

\subsection{Feedstock powder}

The Al2139 and Al2139-AlTiB powders were manufactured by ECKA Granules Germany GmbH using nitrogen atomization [34]. Spectrometry analyses were conducted using an LECO chemical analysis unit, and the chemical compositions of the Al2139 and Al2139-AlTiB powders are given in Table 1. The Al2139-AlTiB powder contains 
Table 1 Chemical compositions (wt.\%) of the Al2139 and Al2139-AlTiB powders measured by inductively coupled plasma atomic emission spectroscopy (ICP-AES)

\begin{tabular}{|c|c|c|c|c|c|c|c|c|c|c|}
\hline Material & $\mathrm{Cu}$ & $\mathrm{Mg}$ & $\mathrm{Ag}$ & $\mathrm{Mn}$ & $\mathrm{Zn}$ & $\mathrm{Fe}$ & $\mathrm{Cr}$ & $\mathrm{Ti}$ & $\mathrm{Si}$ & B \\
\hline Al2139 powder & 4.95 & 0.6 & 0.34 & 0.5 & 0.06 & 0.05 & $<0.01$ & $<0.01$ & 0.05 & - \\
\hline A12139-AlTiB powder & 4.77 & 0.47 & 0.37 & 0.4 & $<0.01$ & 0.05 & $<0.01$ & 0.2 & 0.09 & 0.03 \\
\hline Al2139 specification [35] & $4.5-5.5$ & $0.2-0.8$ & $0.15-0.6$ & $0.2-0.6$ & $<0.25$ & $<0.15$ & $<0.05$ & $<0.05$ & $<0.1$ & - \\
\hline
\end{tabular}

Balance Al

$0.2 \mathrm{wt} . \% \mathrm{Ti}$ and $0.03 \mathrm{wt} . \% \mathrm{~B}$ due to the addition of $4 \mathrm{wt} . \%$ of commercial Al5Ti1B master alloy to the A12139 melt prior to atomization.

The particle-size distribution (PSD) was measured using a laser scattering method with a Malvern Mastersizer 3000. The measured particle parameters such as smallest particle size (d10), mean particle diameter (d50), largest particle size (d90), Sauter mean diameter d( 3,2$)$, and volume mean diameter $\mathrm{d}(4,3)$ are given in Table 2 . The particles were predominantly spherical in shape, with some elongated particles and some satellites observed (Fig. 1). Both powders showed a typical solidification microstructure consisting of $\alpha-\mathrm{Al}$ dendrites and intermetallic phases in the interdendritic regions. Micro-cracks were observed inside the A12139
Table 2 Particle-size distribution for the Al2139 and Al2139-AlTiB powders

\begin{tabular}{lll}
\hline Particle Parameter $(\mu \mathrm{m})$ & Al2139 & Al2139-AlTiB \\
\hline Smallest particle size, d10 & 25.0 & 25.8 \\
Mean particle diameter, d50 & 39.3 & 38.4 \\
Largest particle size, d90 & 61.2 & 56.9 \\
Sauter mean diameter, d(3,2) & 37.1 & 36.7 \\
Volume mean diameter, d $(4,3)$ & 41.5 & 40.1 \\
\hline
\end{tabular}

powder particles while rarely in the Al2139-AlTiB powder. The micro-cracks are considered to be related to hot tearing during solidification. The observation of less micro-cracks in
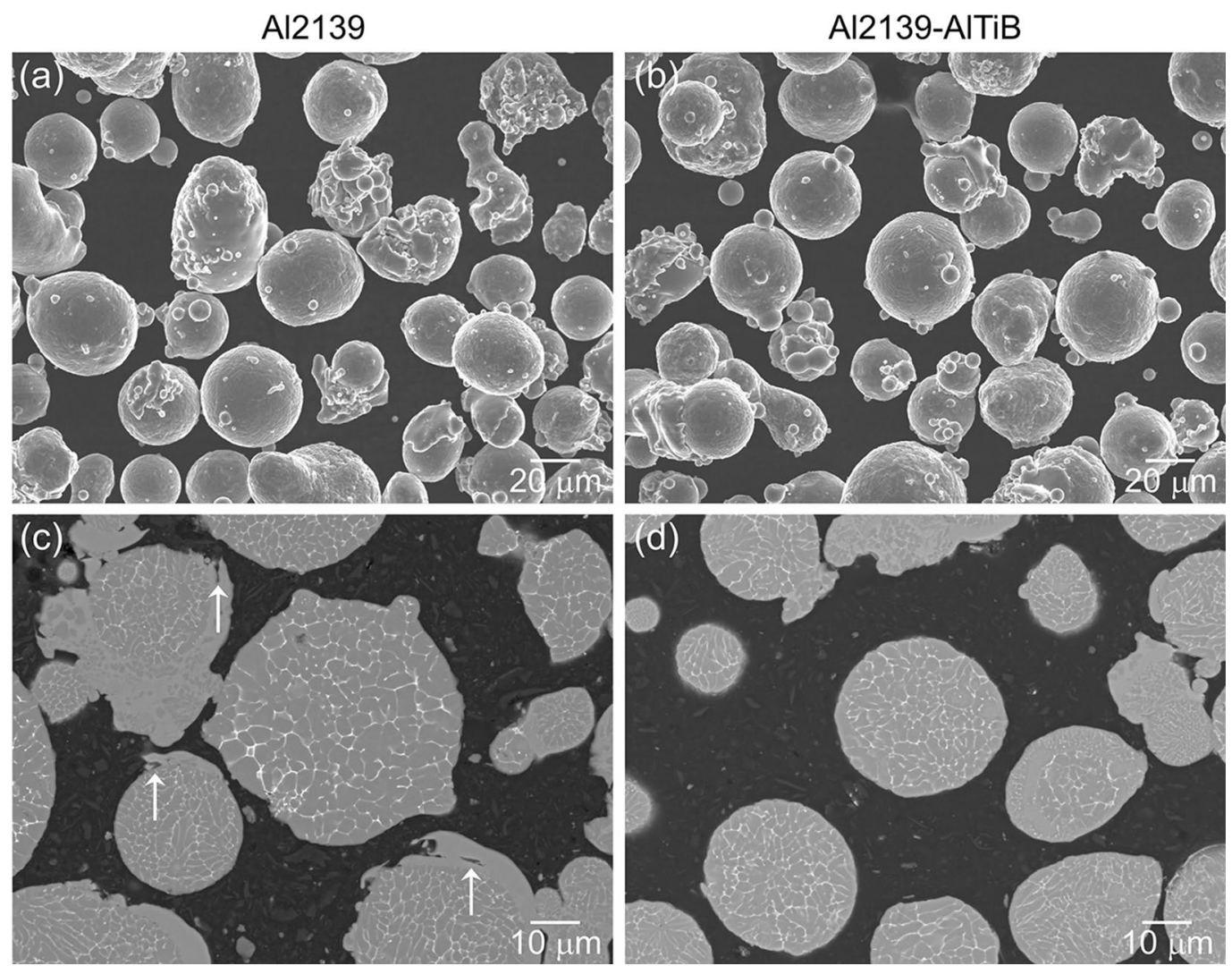

Fig. 1 SEM secondary electron images (a and $\mathbf{b})$ and backscattered electron images (c and $\mathbf{d})$ showing morphology and solidification microstructure of the Al2139 and Al2139-AlTiB powders. The arrows in (c) indicate micro-cracks within the powder particles 
the Al2139-AlTiB powder implies that the grains are refined with the addition of the Al5Ti1B master alloy.

\subsection{Laser powder bed fusion}

An SLM125 machine with a single $400 \mathrm{~W}$ fiber laser was used for printing the samples. A process optimization study was initially undertaken by printing $10 \times 10 \times 10 \mathrm{~mm}^{3}$ cubes. All cubes were printed on supports using a zero offset laser spot size of $\sim 100 \mu \mathrm{m}$. The PBF-LB/M build chamber was flushed with high purity $\mathrm{Ar}$ and the residual oxygen was less than $200 \mathrm{ppm}$. The build platform was preheated to $20{ }^{\circ} \mathrm{C}$ for all samples. The PBF-LB/M parameters were varied by considering the volumetric energy density $\left(E, \mathrm{~J} / \mathrm{mm}^{3}\right)$ defined below

$E=\frac{P}{v h t}$

in which $P$ is the laser power $(\mathrm{W}), \nu$ is the scan speed $(\mathrm{mm} / \mathrm{s}), h$ the hatch spacing $(\mathrm{mm})$, and $t$ is the layer thickness $(\mathrm{mm})$.

Table 3 lists the PBF-LB/M parameters studied, with the volumetric energy density being varied from 30 to $1721 \mathrm{~J} /$ $\mathrm{mm}^{3}$. The powder recoating time was adjusted from 3 to $6 \mathrm{~s}$ for selected levels of volumetric energy density to control the heat loading during printing, but the effect on hot tearing was found to be insignificant and therefore not further considered. A $5 \times 5 \mathrm{~mm}^{2}$ island scan pattern was used to print all cubes and tensile bars, following a $67^{\circ}$ rotation in the scanning strategy between subsequent layers (Fig. 2). Two cubes were printed for the lower energy densities (up to $861 \mathrm{~J} / \mathrm{mm}^{3}$ ) and three cubes for the higher energy densities (above $861 \mathrm{~J} / \mathrm{mm}^{3}$ ). The chemical compositions of the

Table 3 Experimental design for process parameter optimization

\begin{tabular}{lllll}
\hline $\begin{array}{l}\text { Laser } \\
\text { power }(\mathrm{W})\end{array}$ & $\begin{array}{l}\text { Scan speed } \\
(\mathrm{mm} / \mathrm{s})\end{array}$ & $\begin{array}{l}\text { Hatch spac- } \\
\text { ing }(\mathrm{mm})\end{array}$ & $\begin{array}{l}\text { Layer thick- } \\
\text { ness }(\mathrm{mm})\end{array}$ & $\begin{array}{l}\text { Energy } \\
\text { density }(\mathrm{J} / \\
\left.\mathrm{mm}^{3}\right)\end{array}$ \\
\hline 350 & 1373 & 0.17 & 0.05 & 30 \\
350 & 1150 & 0.17 & 0.05 & 35 \\
350 & 1029 & 0.17 & 0.05 & 40 \\
350 & 915 & 0.17 & 0.05 & 45 \\
350 & 824 & 0.17 & 0.05 & 50 \\
200 & 166 & 0.11 & 0.04 & 274 \\
200 & 166 & 0.09 & 0.04 & 335 \\
200 & 166 & 0.07 & 0.04 & 430 \\
200 & 83 & 0.11 & 0.04 & 548 \\
200 & 83 & 0.09 & 0.04 & 669 \\
200 & 83 & 0.07 & 0.04 & 861 \\
200 & 41.5 & 0.11 & 0.04 & 1095 \\
200 & 41.5 & 0.09 & 0.04 & 1339 \\
200 & 41.5 & 0.07 & 0.04 & 1721 \\
\hline
\end{tabular}
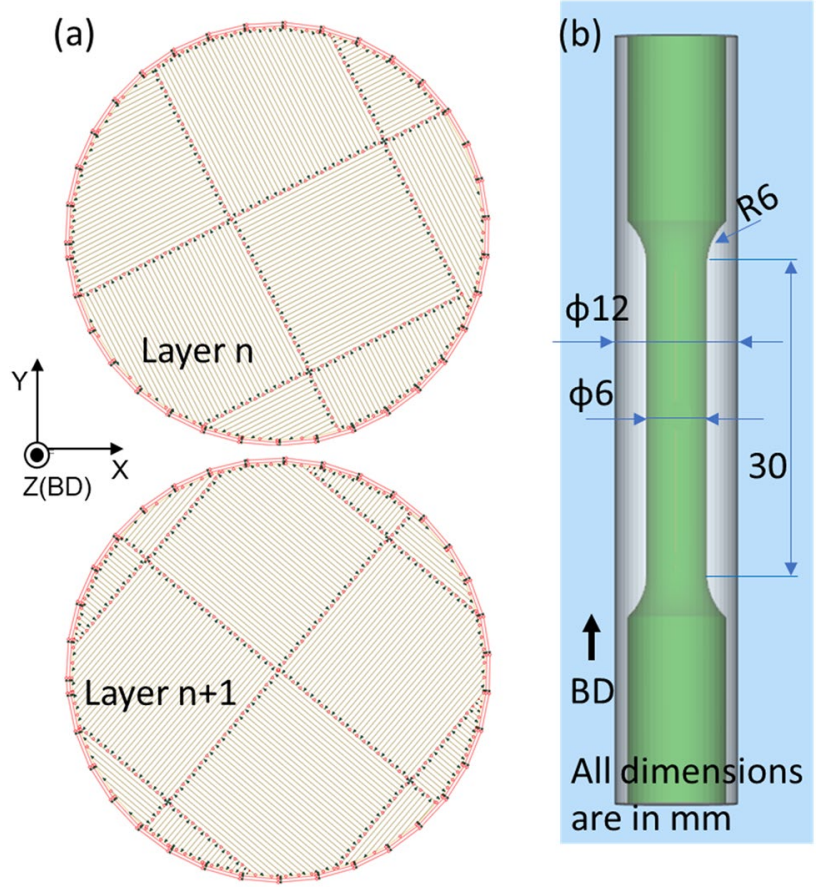

Fig. 2 Schematics showing a the laser scan patterns of a $5 \times 5 \mathrm{~mm}^{2}$ island, with $67^{\circ}$ rotation for the subsequent layer and $\mathbf{b}$ the tensile specimen machined from the vertically printed $12 \mathrm{~mm}$-diameter rod (white)

printed samples were analyzed to assess the effect of process conditions on vaporization of alloying elements.

\subsection{Mechanical testing}

Tensile specimens with a gauge diameter of $6 \mathrm{~mm}$ and a gauge length of $30 \mathrm{~mm}$ as per ASTM E8/E8M [36] were machined from the $12 \mathrm{~mm}$-diameter cylindrical rods that were printed vertically using the optimized PBF-LB/M parameters. The cylindrical rods were fabricated in two different settings, with and without block support structures, to reveal the effect of thermal gradient or heat loading on hot tearing. The block support structures were $5 \mathrm{~mm}$ in height with point contacts.

The tensile specimens were tested in both as fabricated and heat-treated (T6) conditions. The T6 temper consisted of homogenizing at $490{ }^{\circ} \mathrm{C}$ for $24 \mathrm{~h}$, solution treating at $525^{\circ} \mathrm{C}$ for $2 \mathrm{~h}$, followed by water quenching, and aging at $160^{\circ} \mathrm{C}$ for $24 \mathrm{~h}$. The tensile testing was performed at room temperature with a crosshead speed of $1 \mathrm{~mm} / \mathrm{min}$, corresponding to an initial strain rate of $5.6 \times 10^{-4} \mathrm{~s}^{-1}$. Three specimens were tested for each condition. As the tensile tests did not reveal any obvious difference in strength and ductility between the samples printed with and without the supports, only the samples printed with support were used for microstructure characterization and thermomechanical simulation. 

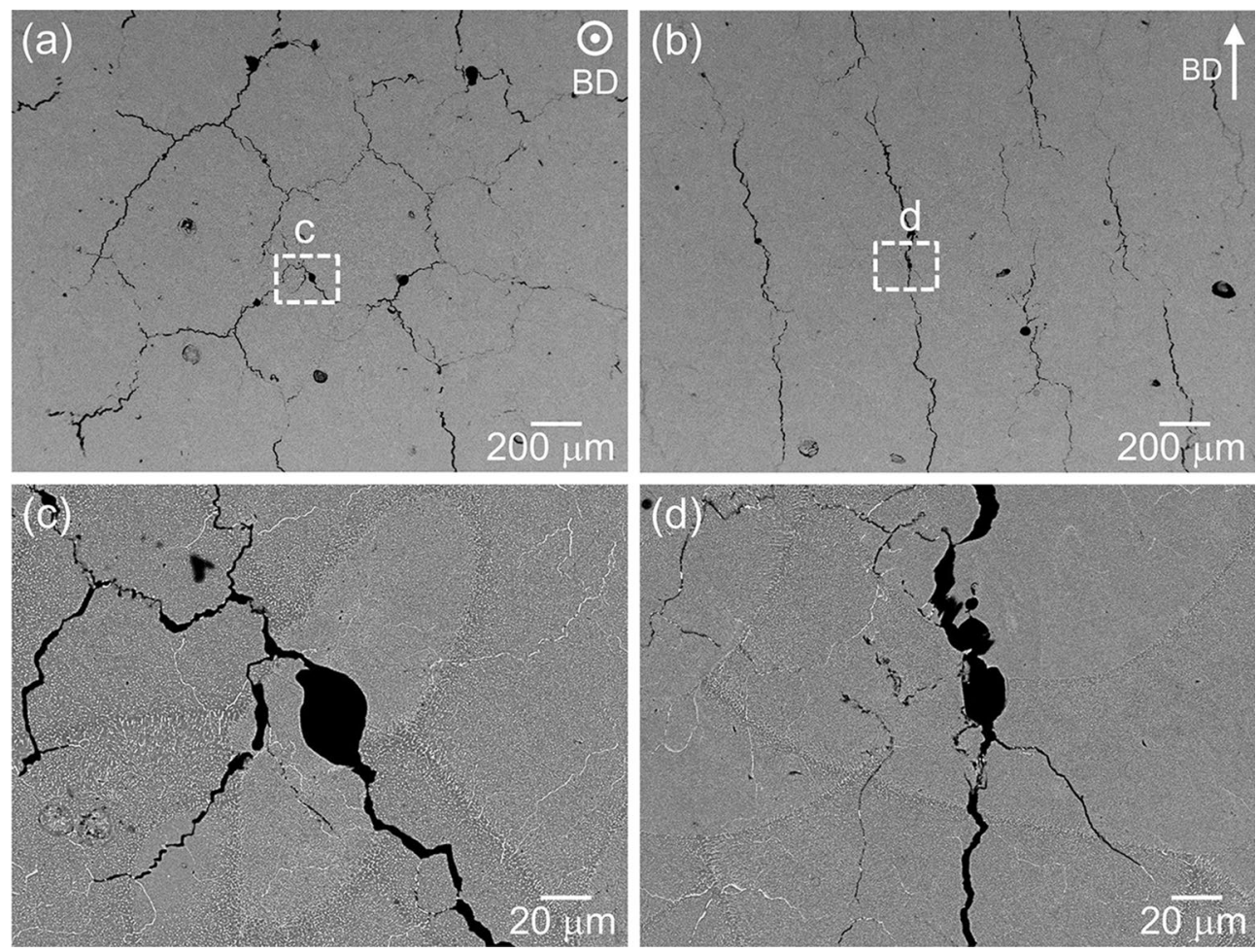

Fig. 3 SEM backscattered electron images of the Al2139 cube printed with a low energy density of $45 \mathrm{~J} / \mathrm{mm}^{3}(P=350 \mathrm{~W}$, $\nu=915 \mathrm{~mm} / \mathrm{s}, h=0.17 \mathrm{~mm}$ and $t=0.05 \mathrm{~mm})$ : a section transverse to

\subsection{Microstructure characterization and defect analysis}

The microstructures were characterized using an FEI Nova NanoSEM 200 FEG-SEM machine equipped with an Oxford Instruments X-Max20 energy-dispersive X-ray (EDX) spectrometer and an Oxford NordlysMax 2 electron back scatter diffraction (EBSD) detector. The samples for EBSD were prepared by conventional metallographic procedures, with the final polishing using $0.25 \mu \mathrm{m}$ silica suspension. To quantify defects, such as cracks (hot tears) and pores, three SEM backscattered electron (BSE) images at a low magnification of $50 \times$ were randomly taken from the transverse section of the PBF-LB/M cubes and analyzed using the image analysis software ImageJ. Cracks and pores were differentiated by the circularity of the defects.

\subsection{Thermomechanical simulation}

Numerical simulation based on a non-linear finite-element method was carried out to analyze the thermomechanical history during PBF-LB/M of A12139. The stress level during PBF$\mathrm{LB} / \mathrm{M}$ of $10 \times 10 \times 10 \mathrm{~mm}^{3}$ cubes was estimated at different energy densities using Simufact Additive 2020 [37]. The temperature-dependent thermomechanical and thermophysical material properties were taken from the literature [38] and the Simufact the building direction, $\mathbf{b}$ section parallel to the building direction, $\mathbf{c}$ enlarged view of the marked area in (a), and (d) enlarged view of the marked area in (b)

material library [39]. An adaptive meshing with a voxel size of $0.166 \mathrm{~mm}^{3}$ was used for the layer-by-layer simulation.

\subsection{Thermodynamic simulation of solidification}

Computherm LLC Pandat computational thermodynamics software (version 2019) and the multi-component PanAl database [40] were used to simulate solidification of Al2139 and Al2139-AlTiB. The Scheil-Gulliver (i.e., non-equilibrium) solidification module was used for the simulation with a maximum temperature step size of $1{ }^{\circ} \mathrm{C}$. Solidification was assumed to begin at the alloy liquidus temperature and to proceed until no liquid remains (i.e., $f_{\mathrm{s}}=1$ ). The overall temperature-solid fraction ( $T$ vs. $f_{\mathrm{s}}$ ) curve and evolution of intermetallic phases were predicted from the simulation. The simulation results were also used to predict the effect of composition on the relative hot tearing susceptibility of each alloy.

\section{Results}

\subsection{Hot tearing susceptibility}

Cracks are prevalent in the PBF-LB/M manufactured A12139 cubes, especially when printed at low energy 

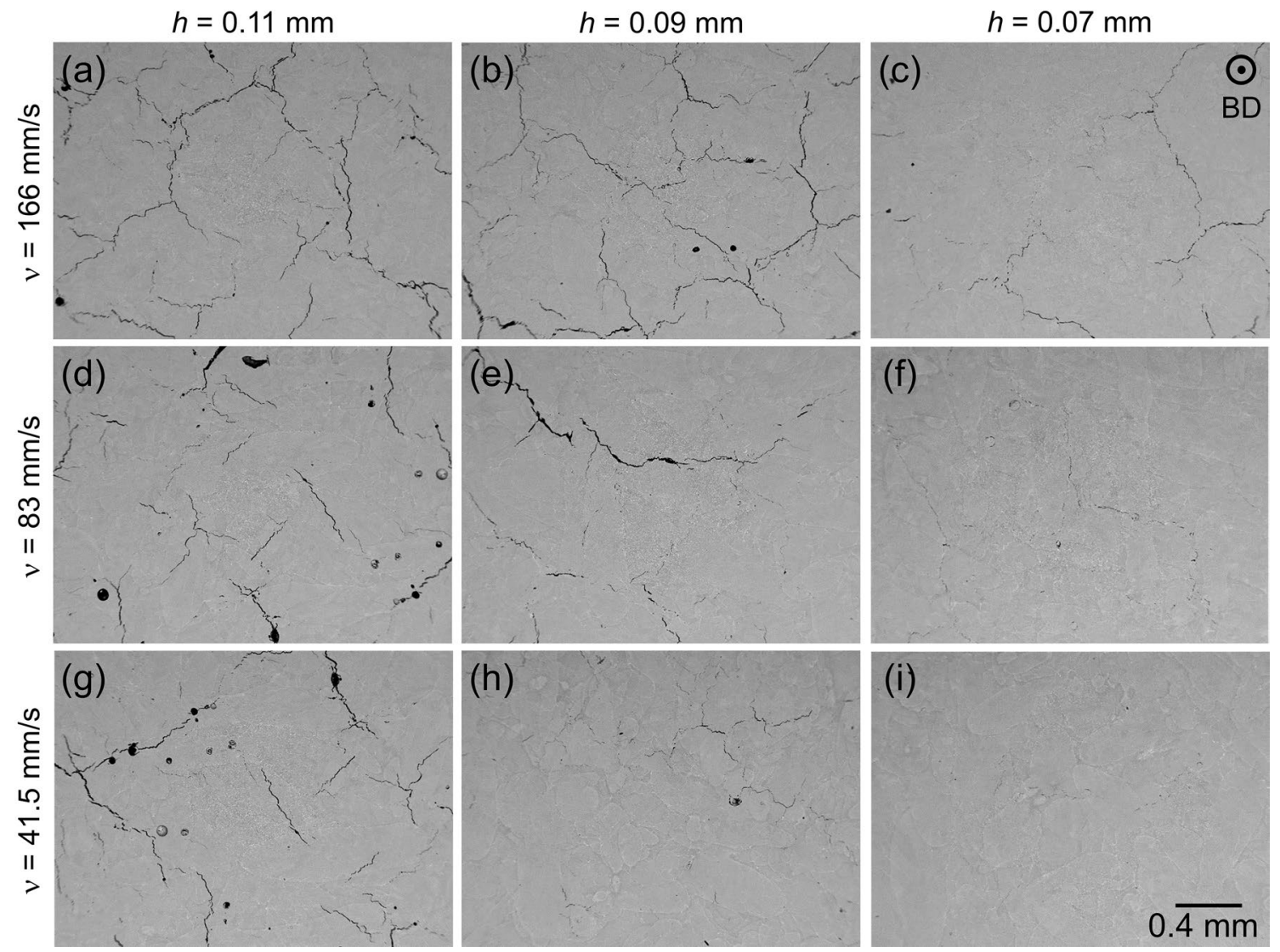

Fig. 4 SEM backscattered electron images transverse to the build direction for the Al2139 cubes printed at $P=200 \mathrm{~W}$ and $t=0.04 \mathrm{~mm}$ with different scan speeds and hatch spacings, which result in energy

densities, as exemplified in Fig. 3. A detailed inspection of the cracks reveals that most cracks are located at the grain boundaries where the intermetallic phases reside in, indicating that these cracks are caused by hot tearing. In addition, cracks appear to extend along the building direction throughout the build height.

Figure 4 shows the cracks observed in the Al2139 cubes printed with different combinations of scan speed and hatch spacing. While the cracks are generally reduced with either decreasing scan speed or decreasing hatch spacing, the hatch spacing appears to be more influential on hot tearing than scan speed. For all three scan speeds, there is a remarkable reduction in the crack area when the hatch spacing is reduced from 0.11 to $0.07 \mathrm{~mm}$. On the other hand, the effect of decreasing scan speed from 166 to $41.5 \mathrm{~mm} / \mathrm{s}$ depends on hatch spacing. Decreasing scan speed does not appear to have much effect in reducing hot tearing for the hatch spacing of $0.11 \mathrm{~mm}$, but the effect is more pronounced for the lower hatch spacings. Similar trends are observed for the Al2139-AlTiB cubes printed using the same PBF-LB/M parameters, which are shown densities of a $274 \mathrm{~J} / \mathrm{mm}^{3}$, b $335 \mathrm{~J} / \mathrm{mm}^{3}$, c $430 \mathrm{~J} / \mathrm{mm}^{3}$, d $548 \mathrm{~J} / \mathrm{mm}^{3}$, e $669 \mathrm{~J} / \mathrm{mm}^{3}, \mathbf{f} 861 \mathrm{~J} / \mathrm{mm}^{3}, \mathbf{g} 1095 \mathrm{~J} / \mathrm{mm}^{3}$, h $1339 \mathrm{~J} / \mathrm{mm}^{3}$, and i $1721 \mathrm{~J} /$ $\mathrm{mm}^{3}$

in Fig. 5. It is noted that, under the same processing condition, the hot tearing susceptibility is apparently lower in the Al2139-AlTiB cubes than in the Al2139 ones.

The quantified hot tearing data are correlated with the energy density, shown in Fig. 6a. Each data point represents the average hot tearing fraction (crack area) from three low magnification SEM backscatter electron images, and the error bars correspond to the standard deviation of three images per sample. In general, the hot tearing susceptibility is reduced with increasing volumetric energy density and is eventually eliminated at higher volumetric energy densities for both Al2139 and Al2139-AlTiB. Furthermore, the extent of hot tearing is always less in the cubes with the AlTiB addition, and consequently, hot tearing is eliminated at a lower energy density for A12139AlTiB compared with Al2139. Specifically, hot tearing in A12139-AlTiB is reduced to below $0.25 \%$ for nearly all processing conditions when the energy density is above $250 \mathrm{~J} / \mathrm{mm}^{3}$. However, relative to the effect of significantly increasing energy density, the effect of adding AlTiB on hot tearing in Al2139 is less potent. 


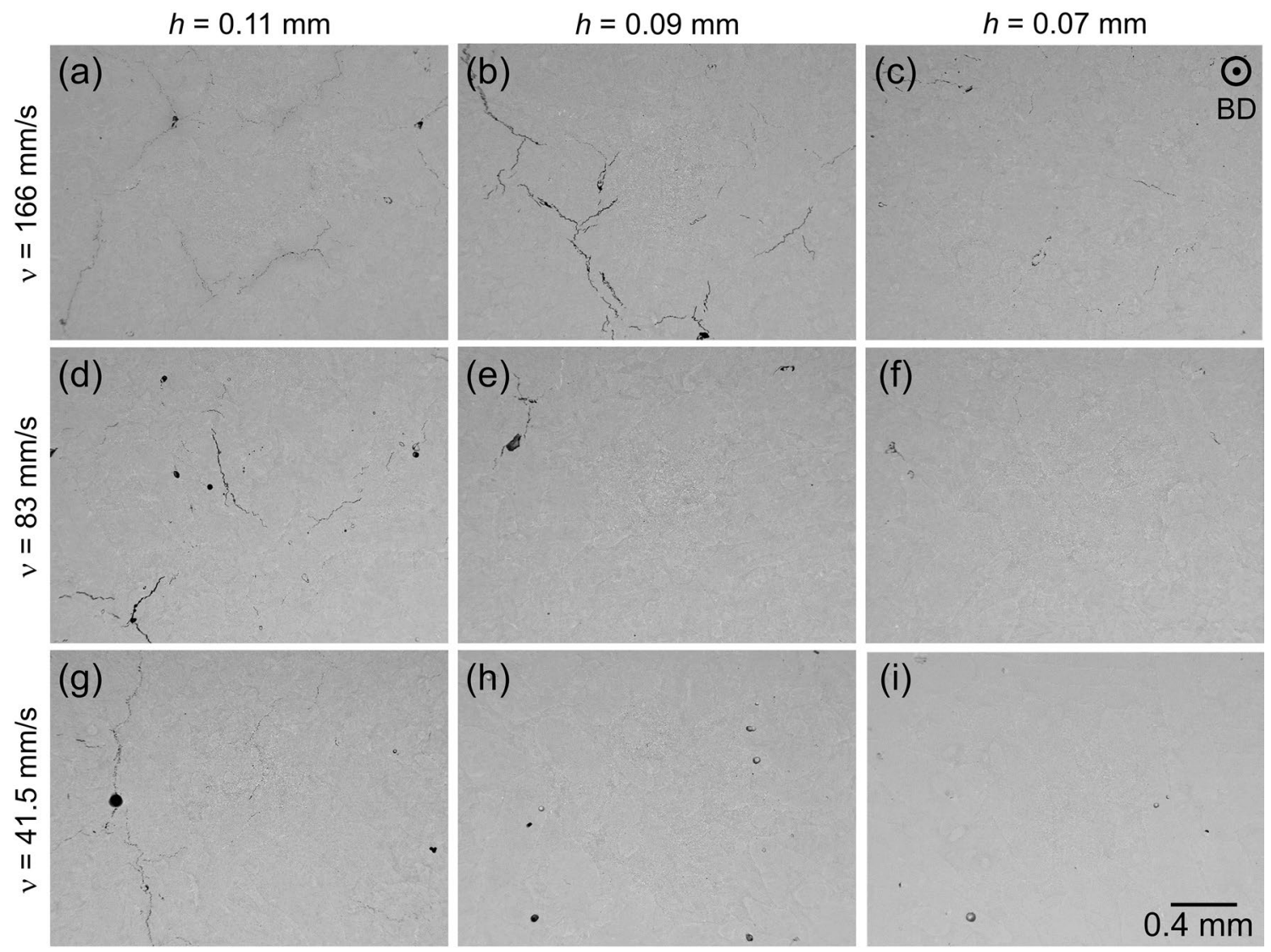

Fig. 5 SEM backscattered electron images transverse to the build direction for the Al2139-AlTiB cubes printed at $P=200 \mathrm{~W}$ and $t=0.04 \mathrm{~mm}$ with different scan speeds and hatch spacings, which result in energy densities of a $274 \mathrm{~J} / \mathrm{mm}^{3}$, b $335 \mathrm{~J} / \mathrm{mm}^{3}$, c $430 \mathrm{~J} / \mathrm{mm}^{3}$, d $548 \mathrm{~J} / \mathrm{mm}^{3}$, e $669 \mathrm{~J} / \mathrm{mm}^{3}$, f $861 \mathrm{~J} / \mathrm{mm}^{3}$, g $1095 \mathrm{~J} / \mathrm{mm}^{3}$, h $1339 \mathrm{~J} /$ $\mathrm{mm}^{3}$, and i $1721 \mathrm{~J} / \mathrm{mm}^{3}$

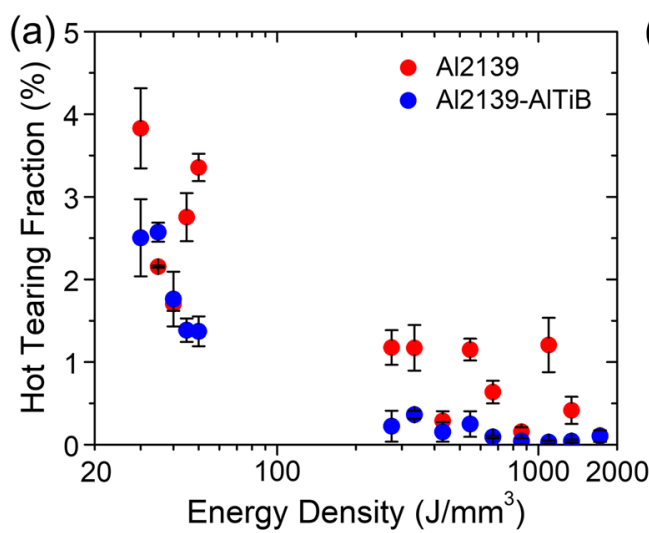

Fig.6 Quantified hot tearing data for the Al2139 and Al2139-AlTiB cubes printed at various PBF-LB/M parameters: a hot tearing fraction plotted against energy density for all cubes specified in Table 3 and $\mathbf{b}$

In addition to correlating hot tearing susceptibility with volumetric energy density, it is also worth quantifying the effect of individual process parameters. The hot tearing data for the cubes printed at $E>250 \mathrm{~J} / \mathrm{mm}^{3}$ are related to

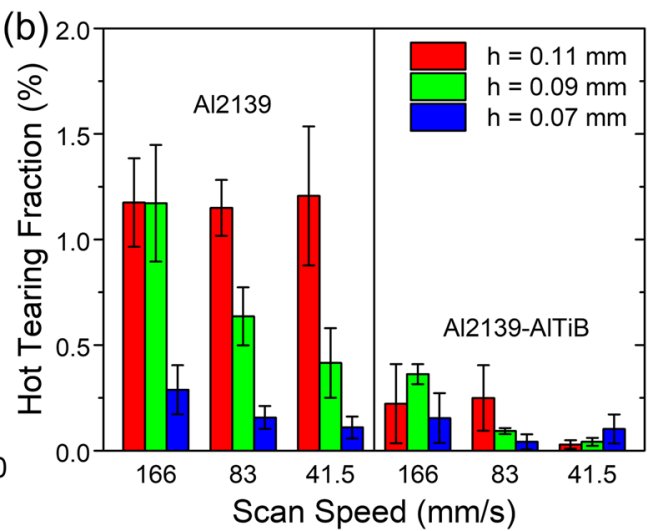

hot tearing fractions of the cubes printed at $E>250 \mathrm{~J} / \mathrm{mm}^{3}$ showing the effects of laser scan speed and hatch spacing

laser scan speed and hatch spacing, shown in Fig. 6b. As observed in Figs. 4 and 5, hot tearing tends to decrease with either decreasing hatch spacing or decreasing scan speed, with the effect of decreasing hatch spacing being 
more significant. It is noted that this tendency is less obvious for Al2139-AlTiB, since the extent of hot tearing is already very low due to grain refinement.

Based on the above observations, the volumetric energy density of $1721 \mathrm{~J} / \mathrm{mm}^{3}$ is provisionally selected if the subsequent analysis of the chemical composition meets specifications.

\subsection{Loss of Mg during PBF-LB/M}

Significant loss of Mg up to $60 \%$ occurred in the PBF$\mathrm{LB} / \mathrm{M}$ cubes at higher energy densities. Table 4 shows the composition analysis for the Al2139 and Al2139-AlTiB cubes printed at the highest density, i.e., $1721 \mathrm{~J} / \mathrm{mm}^{3}$. However, the composition is still within the specification. Hence, the energy density $1721 \mathrm{~J} / \mathrm{mm}^{3}$ can be selected as a preferred key PBF-LB/M parameter for A12139. The loss of $\mathrm{Mg}$ during PBF-LB/M at high energy densities is a known issue for high strength $\mathrm{Al}$ alloys [41-44] and is caused by evaporation. $\mathrm{Mg}$ has a relatively low evaporation temperature $\left(1090^{\circ} \mathrm{C}\right)$ and the local temperature during PBF-LB/M at high energy densities can well exceed this temperature. Although the reduced $\mathrm{Mg}$ contents in the A12139 and Al2139-AlTiB cubes printed at the highest density are still within the specification, the loss of $\mathrm{Mg}$ could influence hot tearing susceptibility and mechanical properties, which will be discussed later.
Table 4 ICP-AES analyzed chemical compositions (wt. \%) of the Al2139 and Al2139-AlTiB cubes printed at an energy density of $1721 \mathrm{~J} / \mathrm{mm}^{3}$

\begin{tabular}{lllllc}
\hline Material & $\mathrm{Cu}$ & $\mathrm{Mg}$ & $\mathrm{Ag}$ & $\mathrm{Mn}$ & $\mathrm{Ti}$ \\
\hline PBF-LB/M A12139 & 5.11 & 0.28 & 0.46 & 0.46 & - \\
Al2139 powder & 4.95 & 0.6 & 0.34 & 0.5 & $<0.01$ \\
PBF-LB/M A12139-AlTiB & 4.91 & 0.23 & 0.38 & 0.38 & 0.21 \\
Al2139-AlTiB powder & 4.77 & 0.47 & 0.37 & 0.4 & 0.2 \\
\hline
\end{tabular}

Balance Al. For comparison, the compositions of the powders are also included

\subsection{Microstructure characterization}

The microstructures of the Al2139 and Al2139-AlTiB cubes printed at different volumetric energy densities were characterized by EBSD orientation maps parallel to the build direction which are shown in Fig. 7. The grain size was measured from the orientation maps by weighed area fraction and is plotted in Fig. 8. Columnar grains remain to be the main feature along the build direction in each case. With increasing energy density, there is no apparent change in the grain morphology for both Al2139 and Al2139-AlTiB, but the grains tend to be coarser at higher energy densities. It is worth noting that, especially for $\mathrm{Al} 2139$, the grain size range is wider at higher energy densities, indicating that the grains have become less uniform with increasing energy density. With the addition of AlTiB,
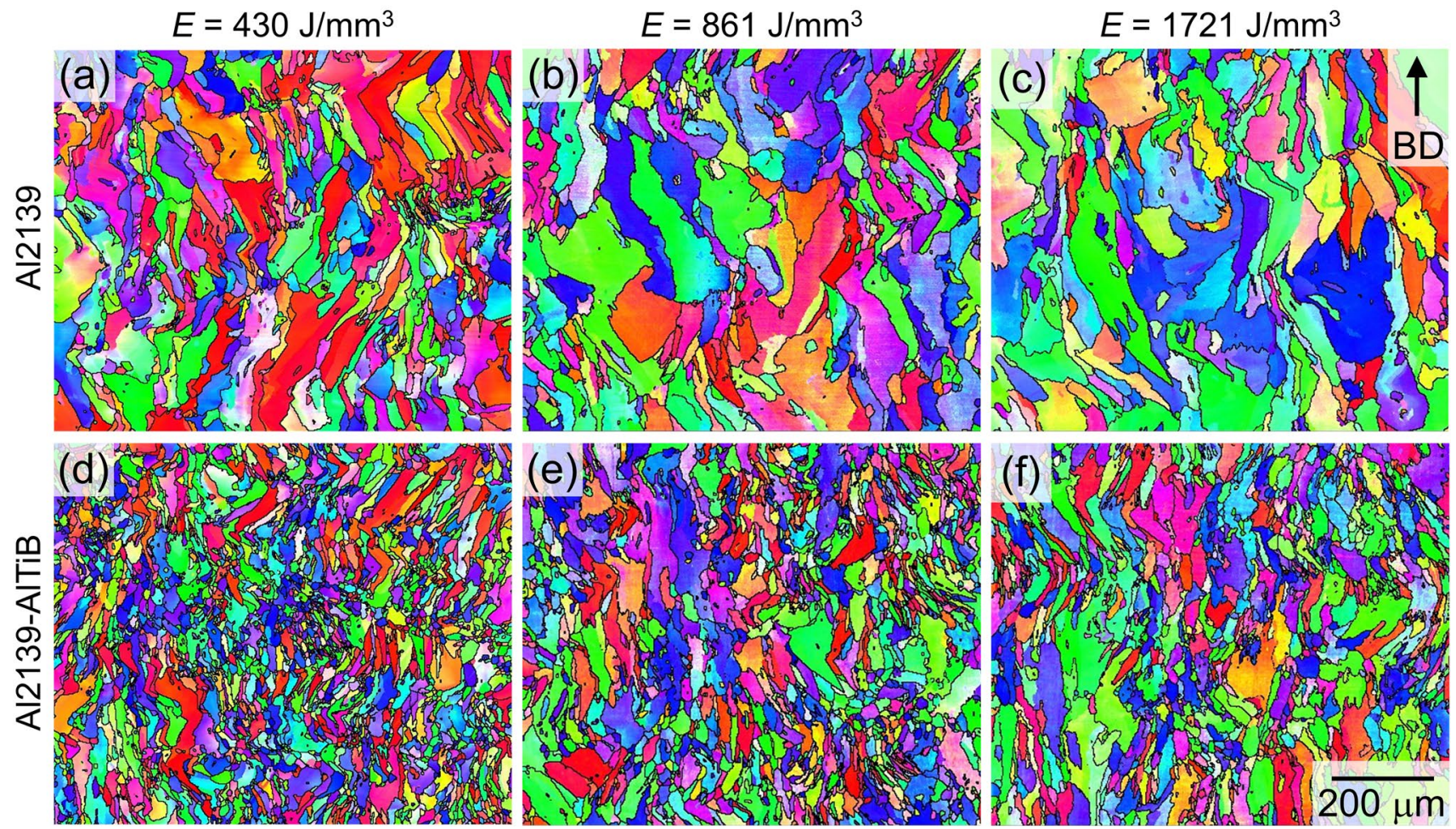

Fig. 7 EBSD orientation maps parallel to the build direction for the Al2139 and Al2139-AlTiB cubes printed at different energy densities 

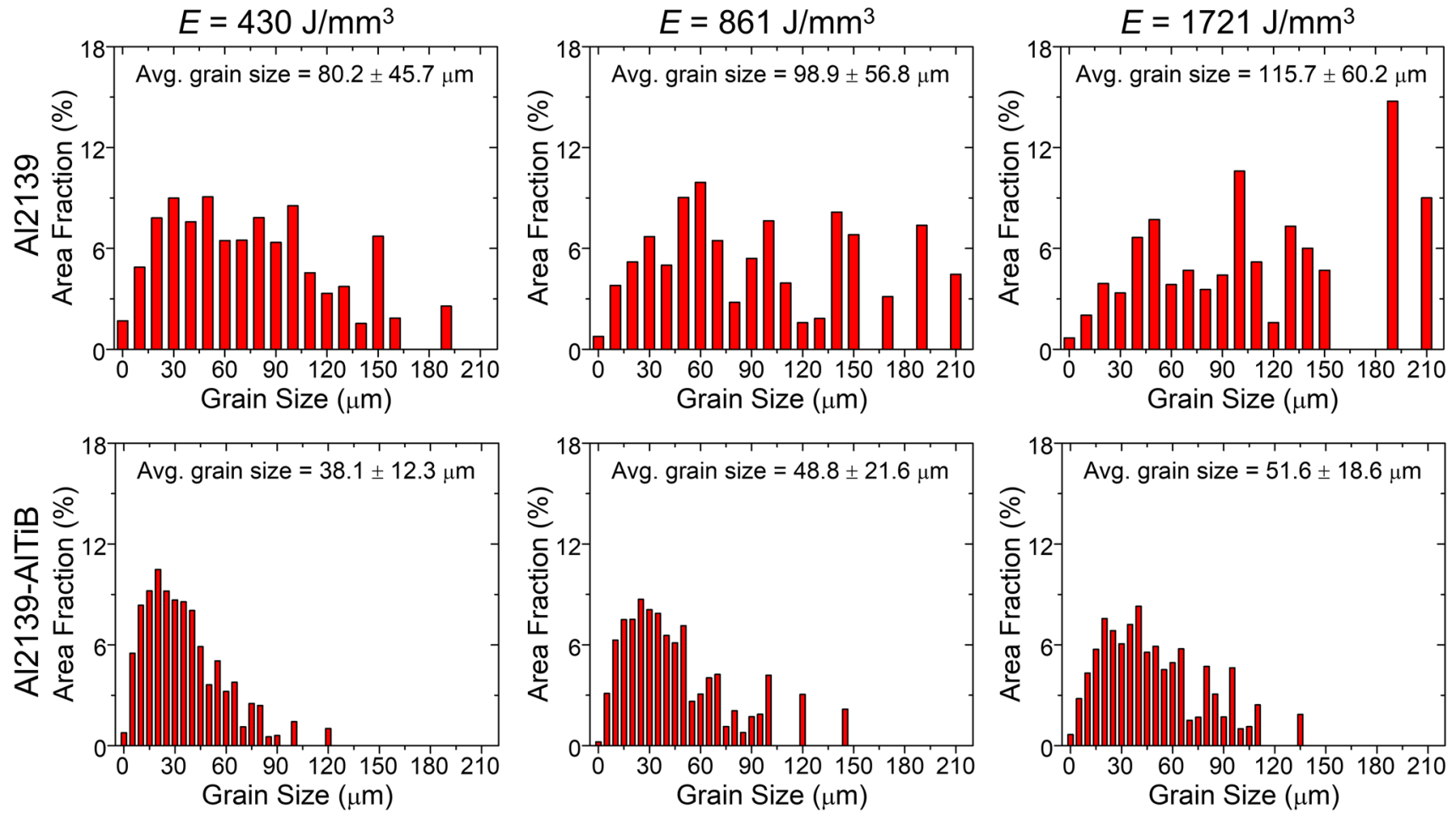

Fig. 8 Histograms of grain size distribution obtained from the EBSD orientation maps in Fig. 7 for the Al2139 and Al2139-AlTiB cubes printed at different energy densities

significant grain refinement has occurred in the Al2139-AlTiB cubes, but the grains remain predominantly columnar along the building direction, rather than equiaxed.

\subsection{Analysis of the effects of the PBF-LB/M parameters on hot tearing by thermomechanical simulation}

Simufact Additive 2020 was used to simulate the evolution of the thermally accumulated residual stress in PBF-LB/M manufactured A12139. Studies have shown that the residual stress decreases with increasing energy density (heat input) due to the slower cooling rate in the melt pool [45]. The simulated residual stress distributions in the Al2139 cubes printed at different scan speeds and hatch spacings are shown in Figs. 9 and 10. The simulations represent the residual stress in the mid-plane of a $10 \times 10 \times 10 \mathrm{~mm}^{3}$ cube. A clear increase in the residual stress is predicted with increasing scan speed during PBF-LB/M. Residual stresses higher than the yield strength ( 110 MPa, Fig. 10) are predicted for scan speeds above $100 \mathrm{~mm} / \mathrm{s}$. On the other hand, Fig. 10 reveals that the residual stress is not affected by changing hatch spacing. While the effect of scan speed on residual stress from the simulations is consistent with the hot tearing tendency shown in Fig. 6b, there is a clear discrepancy between the simulated residual stress and the hot tearing results with respect to the effect of hatch spacing. This discrepancy will be discussed later.

\subsection{Analysis of the effects of AITiB addition and loss of Mg on hot tearing by thermodynamic simulation of solidification}

The susceptibility of $\mathrm{Al}$ alloys to solidification cracking or hot tearing is known to be sensitive to the alloy composition $[46,47]$. A previous study on laser melting of $\mathrm{Al}-\mathrm{Zn}-\mathrm{Mg}-\mathrm{Cu}$ alloy showed that an increase in the amount of $\mathrm{Zn}+\mathrm{Mg}+\mathrm{Cu}$ can enhance crack initiation at the bottom of the melt pool and increase the probability of severe hot cracking [48]. The potential influences arising from the composition changes due to the addition of AlTiB and the loss of Mg on hot tearing susceptibility of the current Al2139 are assessed below.

Figure 11a predicts the solidification sequence of Al2139 and Al2139-AlTiB for the compositions before PBF-LB/M (powder) and after PBF-LB/M. There is an initial temperature decrease from 740 to $646{ }^{\circ} \mathrm{C}$ for Al2139-AlTiB at $f_{\mathrm{s}}<0.005\left(f_{\mathrm{s}}\right.$ is faction of solid $)$, due to the predicted formation of $\mathrm{Al}_{3} \mathrm{Ti}$ particles in the melt pool preceding the nucleation of primary Al grains. After that, the curves for the four alloy compositions are similar as the primary 
(a) Equivalent stress [MPa] $v=1029 \mathrm{~mm} / \mathrm{s}$

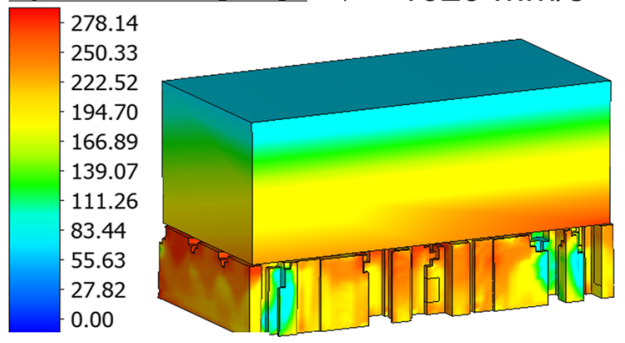

(c) Equivalent stress [MPa] $\quad v=83 \mathrm{~mm} / \mathrm{s}$

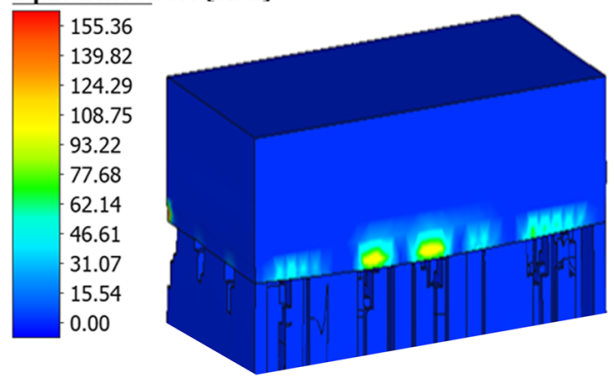

(b) Equivalent stress [MPa] $v=166 \mathrm{~mm} / \mathrm{s}$

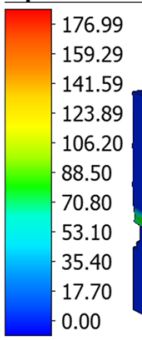

(d) Equivalent stress [MPa] $\quad v=41.5 \mathrm{~mm} / \mathrm{s}$

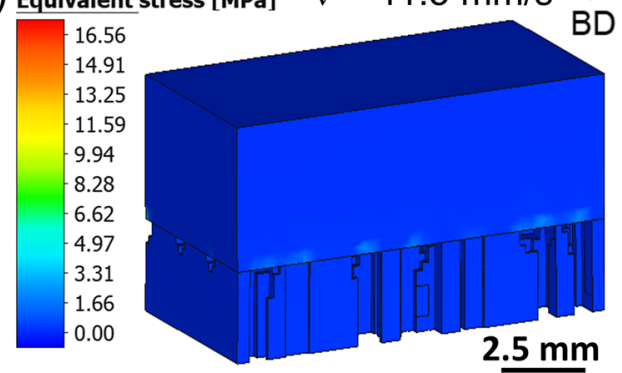

Fig. 9 Simulated residual stress distributions in the Al2139 cubes printed at $P=200 \mathrm{~W}, h=0.07 \mathrm{~mm}$, and $t=0.04$ mm with different scan speeds. Note the difference in the equivalent stress scale in (a-d)

(a)

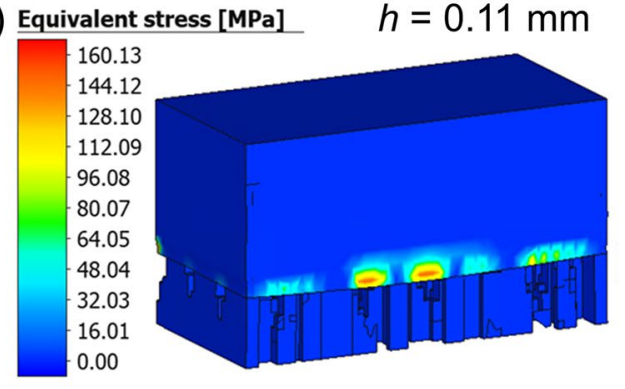

(b)

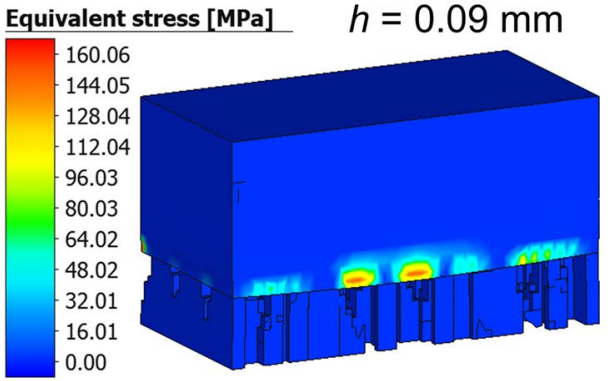

(C) Equivalent stress [MPa]

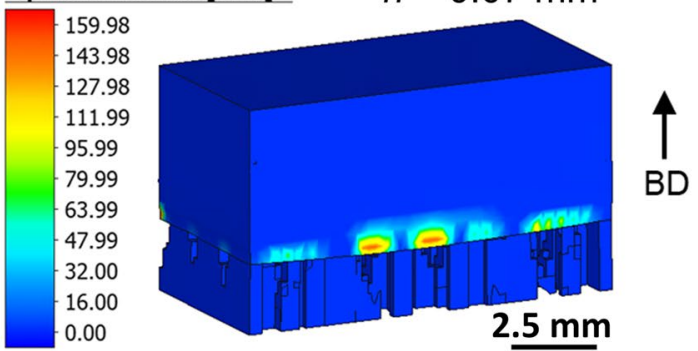

Fig. 10 Simulated residual stress distributions in the Al2139 cubes printed at $P=200 \mathrm{~W}, \nu=83 \mathrm{~mm} / \mathrm{s}$, and $t=0.04 \mathrm{~mm}$ with different hatch spacings

$\mathrm{Al}$ grows. Differences in the curves are first noted around $f_{\mathrm{s}} \sim 0.65$ when intermetallic phases are predicted to form, and the differences are particularly evident for $f_{\mathrm{s}} \geq 0.9$. The composition change induced by PBF-LB/M causes a shift in the $T$ vs. $f_{\mathrm{s}}$ (temperature vs. fraction of solid) curve to higher temperatures for a constant $f_{\mathrm{s}}$ value for both A12139 and Al2139-AlTiB, due to the predicted formation of a greater amount of $\theta-\mathrm{Al}_{2} \mathrm{Cu}$ beginning at $f_{s} \sim 0.9$ and of a lower amount of the $\mathrm{S}-\mathrm{Al}_{2} \mathrm{CuMg}$ phase during the terminal stages of solidification (i.e., $f_{\mathrm{s}}>0.96$ ), as shown in Fig. 11b. 

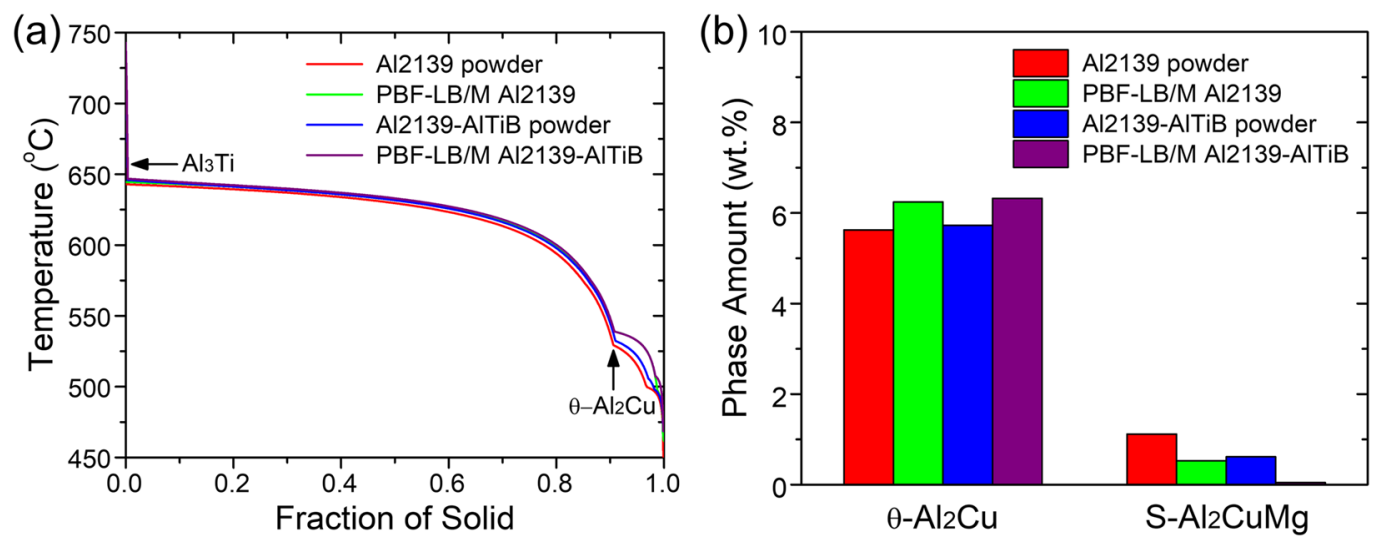

Fig. 11 Pandat analysis of the effects of the composition changes due to the AlTiB addition and $\mathrm{Mg}$ loss during PBF-LB/M $\left(E=1721 \mathrm{~J} / \mathrm{mm}^{3}\right)$ on the $\mathbf{a} \mathrm{T}$ vs. $\mathrm{f}_{\mathrm{s}}$ curve and $\mathbf{b}$ formation of $\theta-\mathrm{Al}_{2} \mathrm{Cu}$ and $\mathrm{S}-\mathrm{Al}_{2} \mathrm{CuMg}$ phases at the end of solidification

To estimate the effect of the loss of $\mathrm{Mg}$ on the relative crack susceptibility, the numerical hot tearing index (HTI) developed by Easton et al. [49] is calculated from the $T v s$. $f_{\mathrm{s}}$ curves by

$H T I_{E}=\int_{T_{0}}^{T_{c o}} f_{s}(T) d T$.

In Eq. (2), $f_{\mathrm{s}}(T)$ is the solid fraction, $\mathrm{T}$ is the melt temperature, $T_{0}$ is the temperature corresponding to coherency, the point at which solid grains begin to impinge upon one another to form a solid skeleton and the flow of the remaining liquid becomes interdendritic, and $T_{\mathrm{co}}$ is the temperature corresponding to coalescence, the point at which the solid skeleton is sufficiently interconnected to take on the characteristics of a solid. A schematic representation of the determination of $\mathrm{HTI}_{\mathrm{E}}$ from the $T$ vs. $f_{\mathrm{s}}$ curves is shown in Fig. 12a for the feedstock Al2139 powder and PBF-LB/M Al2139-AlTiB. A large value of $\mathrm{HTI}_{\mathrm{E}}$ suggests that the alloy is in the mushy state (i.e., between $T_{0}$ and $T_{c o}$ ) for a long duration, during which liquid feeding is restricted and strain can accumulate, resulting in a high susceptibility to hot tearing.

In addition to the $T$ vs. $f_{\mathrm{s}}$ curve, the calculation of $\mathrm{HTI}_{\mathrm{E}}$ requires the selection of the coherency and coalescence points. In the current analysis, coherency is assumed to occur at $f_{s}=0.7$ for all alloys, since the $T v s$. $f_{\mathrm{s}}$ curves are similar up to this point. Furthermore, $\mathrm{HTI}_{\mathrm{E}}$ is more sensitive to the selection of the coalescence point compared to coherency [49]. Coalescence occurs when $f_{\mathrm{s}} 1$, but the determination of the exact value is not straightforward. For the purpose of this analysis, coalescence solid fractions $\left(f_{\mathrm{s}, \mathrm{co}}\right)$ of 0.95 , 0.97 , and 0.98 have been used to calculate $\mathrm{HTI}_{\mathrm{E}}$ for the four alloy compositions, shown in Fig. 12b. The calculated $\mathrm{HTI}_{\mathrm{E}}$ value for all alloys increases with increasing $f_{\mathrm{s}, \mathrm{co}}$ (decreasing $T_{\text {co }}$ ), since the integration range increases. Nevertheless, it can be seen from Fig. 12b that the composition change caused by the loss of Mg during PBF-LB/M reduces the hot tearing susceptibility for both Al2139 and Al2139-AlTiB by between 9.2 and $19.0 \%$, depending on the selection of $f_{\mathrm{s}, \mathrm{co}}$.
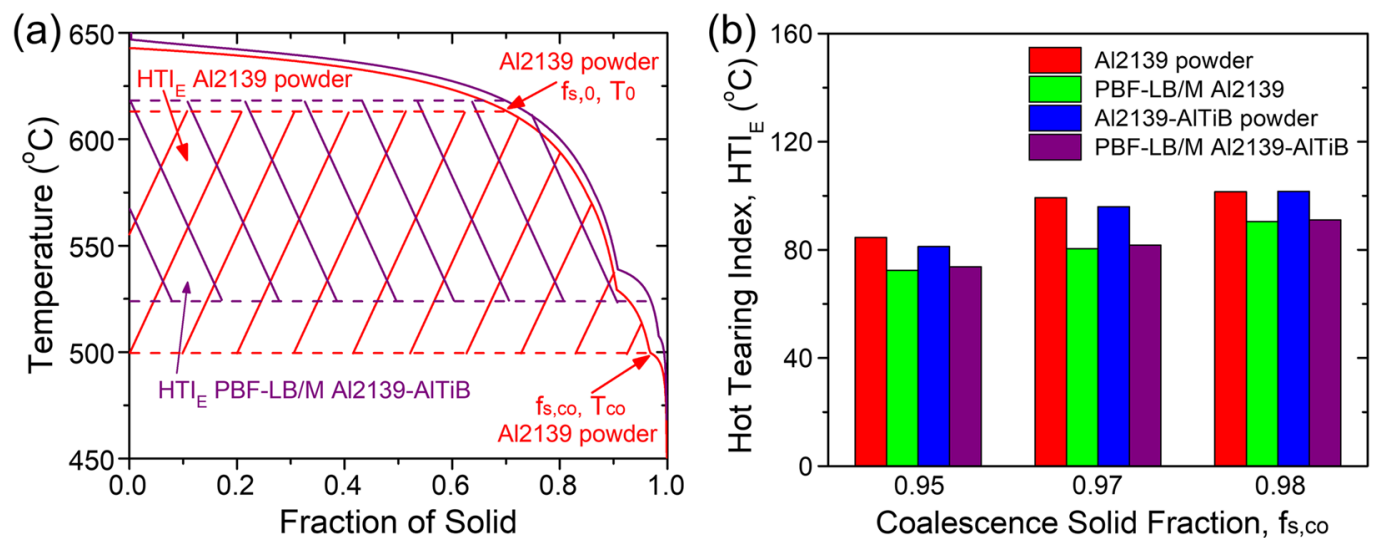

Fig. 12 a Schematic representation of the determination of $\operatorname{HTI}_{\mathrm{E}}$ from the $T$ vs. $f_{s}$ curve $\left(f_{s, 0}=0.7, f_{s, c o}=0.97\right)$ for the $\mathrm{Al} 2139$ and $\mathrm{Al} 2139-\mathrm{AlTiB}$ compositions before and after PBF-LB/M $\left(E=1721 \mathrm{~J} / \mathrm{mm}^{3}\right)$ and $\mathbf{b} \mathrm{HTI}_{\mathrm{E}}$ values calculated for several $f_{s, c o}$ values for the four alloy compositions 
Figure $12 \mathrm{~b}$ suggests that the compositional difference in the alloy due to just the addition of AlTiB is predicted to lead to a minor decrease in hot tearing susceptibility for $\operatorname{Al} 2139$ (4.0\% and $3.4 \%$ for $f_{\mathrm{s}, \mathrm{co}}$ values of 0.95 and 0.97 , respectively). In addition, it is known that the coherency of solid grains tends to shift to higher $f_{\mathrm{s}}$ (i.e., lower $T_{0}$ ) values for more refined microstructures [17, 49]. Therefore, the effect of grain refinement on hot tearing can be predicted, at least for demonstration purposes, by re-calculating $\mathrm{HTI}_{\mathrm{E}}$ using a larger $f_{\mathrm{s}, 0}$ value for the Al2139-AlTiB composition. For example, the hot tearing susceptibility of the Al2139AlTiB powder is reduced by $10.2 \%$ for $f_{\mathrm{s}, \mathrm{co}}=0.95$ and $8.7 \%$ for $f_{\mathrm{s}, \mathrm{co}}=0.97$ compared to the $\mathrm{A} 12139$ powder when $f_{\mathrm{s}, 0}=0.75$ is assumed. Similarly, the hot tearing susceptibility of the PBF-LB/M Al2139-AlTiB is reduced by $5.4-6.0 \%$ compared to the PBF-LB/M Al2139, depending on $f_{\mathrm{s}, \mathrm{co}}$.

\subsection{Mechanical properties}

The selected energy density of $1721 \mathrm{~J} / \mathrm{mm}^{3}$ and the corresponding PBF-LB/M parameters, i.e., $P=200 \mathrm{~W}$, $\nu=41.5 \mathrm{~mm} / \mathrm{s}, h=0.07 \mathrm{~mm}$, and $t=0.04 \mathrm{~mm}$, were used to fabricate tensile specimens for both Al2139 and Al2139AlTiB. Even though Al2139-AlTiB cube samples were printed without hot tearing at $1095 \mathrm{~J} / \mathrm{mm}^{3}$, the tensile specimens were printed at $1721 \mathrm{~J} / \mathrm{mm}^{3}$ for direct comparison of results. The tensile properties of the PBF-LB/M manufactured Al2139 and Al2139-AlTiB in the as-printed state as well as in the heat-treated (T6) condition are presented in Fig. 13. For comparison purposes, the minimum military specification for Al2139 T8 [50] and the ASM standard for 201 T6 [51] are also included in Fig. 13. As expected, the strengths of the as-printed Al2139 and Al2139-AlTiB are significantly improved by the $\mathrm{T} 6$ heat treatment, while the tensile ductility is similar. Compared with the wrought or cast counterparts, the PBF-LB/M manufactured Al2139 and Al-2139-AlTiB in the T6-treated condition have lower yield strength, similar tensile strength but better ductility. It is worth noting that the addition of AlTiB has not resulted in improvements in strength as expected. In fact, the PBF-LB/M manufactured Al2139-AlTiB shows slightly lower yield strength and tensile strength, but higher ductility than the PBF-LB/M manufactured A12139 in both as-printed and T6-treated conditions.

\section{Discussion}

\subsection{Effect of the PBF-LB/M parameters on hot tearing susceptibility of Al2139}

The current study indicates that the selection of PBF$\mathrm{LB} / \mathrm{M}$ parameters has a significant influence on hot tearing susceptibility of A12139, with hot tearing being reduced by

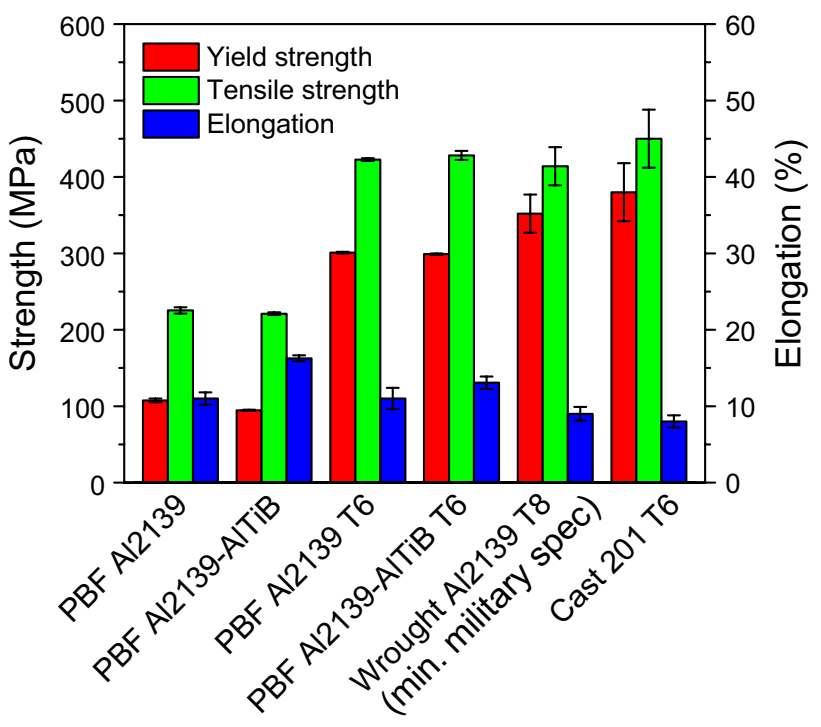

Fig. 13 Mechanical properties of the PBF-LB/M manufactured $\mathrm{Al} 2139$ and Al2139-AlTiB $\left(E=1721 \mathrm{~J} / \mathrm{mm}^{3}\right)$ in the as-printed and heat-treated (T6) conditions. Three samples were printed and tested for each condition. The wrought and cast counterparts, i.e., the minimum military specification for Al2139 T8 [50] and the ASM standard for 201 T6 [51], are also shown for comparison

increasing energy density and being eliminated at higher energy densities. Previous studies [2, 13, 52, 53] have shown that an energy density in the range of $60-350 \mathrm{~J} /$ $\mathrm{mm}^{3}$ is needed to achieve desirable densification (>99\%) for Al-Cu based alloys by PBF-LB/M. In this study, the lowest energy density to achieve desirable densification for $\mathrm{Al} 2139$ without AlTiB addition is $430 \mathrm{~J} / \mathrm{mm}^{3}$. It is worth mentioning that the energy density should be used with care when transferring between different machine configurations, and should not be used as a universal parameter.

The reduced hot tearing with increasing energy density can be mainly attributed to the reduced thermally accumulated residual stress due to the lower cooling rate of melt pool at higher energy densities (Fig. 9). The accumulated residual stress in the printed samples presents a form of external restraint on the subsequent layers, which, when in tension, can lead to grain separation in the mushy zone of melt pool. Hot tearing will occur if the extent of grain separation caused by the accumulated residual stress cannot be compensated by grain growth and interdendritic flow of the remaining liquid [54]. It should be pointed out that the extensive hot tearing observed in the cubes at very low energy densities $\left(E \leq 50 \mathrm{~J} / \mathrm{mm}^{3}\right)$ may further be linked to incomplete fusion due to local insufficient liquid filling. On the other hand, the severe loss of $\mathrm{Mg}$ due to evaporation at very high energy densities may have a small beneficial to reducing hot tearing tendency, as predicted in Fig. 12.

In addition to the effect of overall energy input, it is worth discussing the effects of individual process parameters on hot 
tearing, which provide a different perspective to understand the occurrence of hot tearing. Nie et al. [14] showed that the overall quality and hot tearing susceptibility of $\mathrm{Al}-\mathrm{Cu}$ alloys produced by PBF-LB/M depend on the parameter combination of scan speed and hatch spacing, with crack-free samples achievable only within a narrow window. The decrease in hot tearing with decreasing scan speed in this study is aligned with the thermomechanical simulations in that lower scan speeds result in lower residual stress in the printed material (Fig. 9). Moreover, decreasing scan speed has been reported in several prior studies to decrease hot tearing during PBF$\mathrm{LB} / \mathrm{M}$ of Al-Cu alloys [2, 12-14]. The underlying mechanism is similar, i.e., lowering scan speed increases the volumetric energy density and reduces the cooling rate of the melt pool, thereby allowing sufficient time for the remaining liquid phase to flow into interdendritic regions to prevent tearing.

Decreasing hatch spacing also results in a greater energy density, akin to reducing scan speed. In principle, a small hatch spacing corresponds to a significant overlap between adjacent tracks, and consequently, a relatively large amount of heat from the melt pool will be conducted through the adjacent layers compared to the previously deposited layer. $\mathrm{Hu}$ et al. [16] have shown that a smaller hatch spacing can result in re-melting of pre-existing cracks in previous melt tracks, which is beneficial to minimizing cracks. The experimental results shown in Figs. 4, 5 and 6 have clearly indicated the strong influence of reducing hatch spacing on eliminating hot cracking. However, the simulation results shown in Fig. 10 indicate that hatch spacing has a negligible effect on the residual stress in the printed samples. This implies that residual stress may not always be the dictating factor for the occurrence of hot tearing, although it is certainly an important contributor.

\subsection{The effect of grain refinement by AITiB on hot tearing in PBF-LB/M of Al2139}

Grain refinement has long been known to be effective in suppressing hot tearing of $\mathrm{Al}$ castings [55]. However, despite grain refinement being a successful technology to reduce hot tearing, the mechanism by which it acts is still not completely clear. It has been suggested that grain refinement can delay the on-set of grain coherency, reduce the amount of load in the solidifying mush [17], ease contraction strain [56], allow for strain to be accommodated at more grain boundaries [57], and even increase capillary pressures holding non-coalesced grains together during solidification [58]. On the downside, fine grains can indeed reduce the permeability of the semi-solid mush. As such, there has been a suspicion that equiaxed grain morphology is a potential contributing factor to hot tearing as well [59].
In this study, the addition of a conventional AlTiB grain refiner is shown to considerably refine grains and reduce hot tearing in PBF-LB/M of Al2139, especially at high energy densities. According to Patel et al. [60], the extra grain refinement observed in PBF-LB/M by AlTiB can be attributed to an increase in thermal undercooling, activating a larger number of nucleants of lower potencies, and a reduction in the size of the nucleation free zone under the high cooling rates and thermal gradients that are typical for AM [61]. While the reduced hot tearing in A12139 is mainly related to grain refinement, the composition changes with the AITiB addition may play a minor role. From the thermodynamic solidification simulations (Fig. 12), the hot tearing susceptibility of the PBF-LB/M Al2139-AlTiB could be reduced by up to $6.0 \%$ compared to the PBF-LB/M Al2139.

It should be pointed out that, relative to the effect of increasing energy density, the effect of adding AlTiB on hot tearing in Al2139 is moderate. This is because the AlTiB addition was not able to achieve a fully equiaxed microstructure. Although there is significant grain refinement by the AlTiB modification, a transition in grain morphology was unexpectedly limited. Nevertheless, the results of this work do provide evidence to suggest that the conventional, and therefore economical, grain refinement approach by inoculation could be technologically effective in achieving grain refinement and suppressing hot tearing in $\mathrm{PBF}-\mathrm{LB} / \mathrm{M}$ of high strength $\mathrm{Al}$ alloys.

\subsection{Mechanical properties}

The tensile test results reveal that the PBF-LB/M Al2139AlTiB has lower yield strength, but better ductility than the PBF-LB/M Al2139 in both as-built and T6 conditions. The lower yield strength observed for the PBF-LB/M Al2139AlTiB is unexpected, since the PBF-LB/M Al2139-AlTiB has a much finer grain structure than the PBF-LB/M Al2139. The observed difference in yield strength is considered to be related to the different $\mathrm{Mg}$ contents. It has been well recognized that $\mathrm{Mg}$ is necessary for the formation of the main strengthening $\Omega-\mathrm{Al}_{2} \mathrm{Cu}$ phase in $\mathrm{Al}-\mathrm{Cu}$ alloys [44]. The presence of $\mathrm{Ag}$ in the alloy intensifies this effect and leads to increased $\Omega$ precipitation along with a refinement in the scale and distribution of precipitates, thus enhancing the precipitation hardening effect in $\mathrm{Al} 2139$ [33]. The better ductility of the PBF-LB/M Al2139-AlTiB relative to the PBF-LB/M Al2139 can also be attributed to the lower Mg content, although grain size may also play a role.

Similarly, the lower yield strengths of the PBF-LB/M $\mathrm{Al} 2139$ and Al2139-AlTiB in the T6 condition compared with their wrought or cast counterparts can be attributed to the significant loss of $\mathrm{Mg}$ as both alloys were printed at a very high volumetric energy density $\left(1721 \mathrm{~J} / \mathrm{mm}^{3}\right)$. The loss 
of $\mathrm{Mg}$ can also explain the differences in ductility between these materials. Hence, the loss of $\mathrm{Mg}$ at high energy densities must be considered when optimizing PBF-LB/M parameters to suppress hot tearing in $\mathrm{Al} 2139$ and other $\mathrm{Al}$ alloys containing volatile elements. Future work should explore an optimized addition of the AlTiB grain refiner in conjunction with the use of a relatively low energy density to achieve crack-free PBF-LB/M Al2139 with mechanical properties matching those of the wrought or cast counterparts.

\section{Conclusions}

In this study, an attempt has been made to reduce hot tearing in PBF-LB/M manufacturing of A2139 through parameter selection and grain refinement. The key findings of this study are:

(1) Increasing energy density can reduce and eventually eliminate hot tearing in A12139. This effect can be attributed to the decrease in the thermal stress that is induced during PBF-LB/M and the loss of $\mathrm{Mg}$ due to evaporation, especially at high energy densities.

(2) The addition of AlTiB, even without creating a fully equiaxed grain structure, can reduce hot tearing in PBF-LB/M of Al2139. Future work should explore an optimized addition of AlTiB toward eliminating hot tearing in this alloy at relatively low energy densities.

(3) The PBF-LB/M Al2139 and Al2139-AlTiB printed at a very high energy $\left(1721 \mathrm{~J} / \mathrm{mm}^{3}\right)$ show lower yield strength but better ductility than their wrought or cast counterparts. The observed differences in mechanical properties can be attributed to the severe loss of $\mathrm{Mg}$ during PBF-LB/M due to the high energy density. It is thus suggested that the loss of $\mathrm{Mg}$ at high energy densities must be considered when optimizing PBF-LB/M parameters to suppress hot tearing in Al2139 and other $\mathrm{Al}$ alloys containing volatile elements.

Acknowledgements The authors acknowledge the facilities, and the scientific and technical assistance of the RMIT Advanced Manufacturing Precinct and the RMIT Microscopy and Microanalysis Facility. M. A. Easton would like to acknowledge DP160100560 which provided background information used to develop the strategy used in this work. M. J. Benoit would like to acknowledge the financial support of the Banting Postdoctoral Fellowship program.

Funding Open Access funding enabled and organized by CAUL and its Member Institutions.

\section{Declarations}

Conflict of interest On behalf of all authors, the corresponding author states that there is no conflict of interest.
Open Access This article is licensed under a Creative Commons Attribution 4.0 International License, which permits use, sharing, adaptation, distribution and reproduction in any medium or format, as long as you give appropriate credit to the original author(s) and the source, provide a link to the Creative Commons licence, and indicate if changes were made. The images or other third party material in this article are included in the article's Creative Commons licence, unless indicated otherwise in a credit line to the material. If material is not included in the article's Creative Commons licence and your intended use is not permitted by statutory regulation or exceeds the permitted use, you will need to obtain permission directly from the copyright holder. To view a copy of this licence, visit http://creativecommons.org/licenses/by/4.0/.

\section{References}

1. Trevisan F et al (2017) On the selective laser melting (SLM) of the AlSi10Mg alloy: process, microstructure, and mechanical properties. Materials 10(1):76

2. Zhang $\mathrm{H}$ et al (2016) Selective laser melting of high strength Al$\mathrm{Cu}-\mathrm{Mg}$ alloys: processing, microstructure and mechanical properties. Mater Sci Eng, A 656:47-54

3. Zhang D et al (2018) Metal alloys for fusion-based additive manufacturing. Adv Eng Mater 20(5): 1700952

4. Ahuja B et al (2014) Fabrication and characterization of high strength $\mathrm{Al}-\mathrm{Cu}$ alloys processed using laser beam melting in metal powder bed. Phys Procedia 56:135-146

5. Simonelli $\mathrm{M}$ et al (2015) A study on the laser spatter and the oxidation reactions during selective laser melting of $316 \mathrm{~L}$ stainless steel, Al-Si10-Mg, and Ti-6Al-4V. Metall and Mater Trans A 46(9):3842-3851

6. Campbell TJ et al (2005) Oxidation of aluminum nanoclusters. Phys Rev B 71(20):205413

7. Zavala-Arredondo $\mathrm{M}$ et al (2017) Laser diode area melting for high speed additive manufacturing of metallic components. Mater Des 117:305-315

8. Lathabai S (2018) Chapter 2-Additive manufacturing of aluminium-based alloys and composites. In: Lumley RN (ed) Fundamentals of aluminium metallurgy. Woodhead Publishing, pp 47-92

9. Aboulkhair NT et al (2019) 3D printing of Aluminium alloys: Additive Manufacturing of Aluminium alloys using selective laser melting. Prog Mater Sci 106:100578

10. Koutny D et al (2018) Influence of scanning strategies on processing of aluminum alloy EN AW 2618 using selective laser melting. Materials 11(2):298

11. Karg MCH et al (2017) Effects of process conditions on the mechanical behavior of aluminium wrought alloy EN AW-2219 (AlCu6Mn) additively manufactured by laser beam melting in powder bed. Micromachines 8(1):23

12. Zhang $\mathrm{H}$ et al (2017) Effect of Zirconium addition on crack, microstructure and mechanical behavior of selective laser melted Al-Cu-Mg alloy. Scripta Mater 134:6-10

13. Wang P et al (2018) Microstructure and mechanical properties of a heat-treatable $\mathrm{Al}-3.5 \mathrm{Cu}-1.5 \mathrm{Mg}-1 \mathrm{Si}$ alloy produced by selective laser melting. Mater Sci Eng A 711:562-570

14. Nie $X$ et al (2018) Analysis of processing parameters and characteristics of selective laser melted high strength $\mathrm{Al}-\mathrm{Cu}-\mathrm{Mg}$ alloys: From single tracks to cubic samples. J Mater Process Technol 256:69-77

15. Nie $X$ et al (2018) Effect of Zr content on formability, microstructure and mechanical properties of selective laser melted $\mathrm{Zr}$ modified Al4.24Cu-1.97Mg-0.56Mn alloys. J Alloys Compds 764:977-986

16. $\mathrm{Hu} \mathrm{Z}$ et al (2021) Cracking criterion for high strength $\mathrm{Al}-\mathrm{Cu}$ alloys fabricated by selective laser melting. Additive Manuf 37:101709 
17. Easton MA, Wang H, Grandfield JF, StJohn DH, Sweet E (2004) An analysis of the effect of grain refinement on the hot tearing of aluminium alloys. Mater Forum 28:224-229

18. Lin S, Aliravci C, Pekguleryuz MO (2007) Hot-tear susceptibility of aluminum wrought alloys and the effect of grain refining. Metall and Mater Trans A 38(5):1056-1068

19. Zhou L et al (2019) Microstructure and tensile property of a novel $\mathrm{AlZnMgScZr}$ alloy additively manufactured by gas atomization and laser powder bed fusion. Scripta Mater 158:24-28

20. Yang KV et al (2018) Columnar to equiaxed transition in $\mathrm{Al}-\mathrm{Mg}(-$ $\mathrm{Sc})-\mathrm{Zr}$ alloys produced by selective laser melting. Scripta Mater 145:113-117

21. Qbau N et al (2020) The crack healing effect of scandium in aluminum alloys during laser additive manufacturing. J Manuf Process 50:241-246

22. Tomus D et al (2010) Electron beam processing of Al-2Sc alloy for enhanced precipitation hardening. Scripta Mater 63(2):151-154

23. Cepeda-Jiménez CM, Prado-Martínez C, Pérez-Prado MT (2018) Understanding the high temperature reversed yield asymmetry in a Mg-rare earth alloy by slip trace analysis. Acta Mater 145:264-277

24. Zhang D et al (2020) Grain refinement of alloys in fusion-based additive manufacturing processes. Metall and Mater Trans A 51(9):4341-4359

25. Martin JH et al (2017) 3D printing of high-strength aluminium alloys. Nature 549(7672):365-369

26. Tan $Q$ et al (2020) Inoculation treatment of an additively manufactured 2024 aluminium alloy with titanium nanoparticles. Acta Mater 196:1-16

27. Opprecht $\mathrm{M}$ et al (2020) A solution to the hot cracking problem for aluminium alloys manufactured by laser beam melting. Acta Mater 197:40-53

28. Xi L et al (2020) Grain refinement in laser manufactured Al-based composites with TiB2 ceramic. J Market Res 9(3):2611-2622

29. Carluccio D et al (2018) Grain refinement of laser remelted Al-7Si and 6061 aluminium alloys with Tibor $\circledR$ and scandium additions. $\mathbf{J}$ Manuf Process 35:715-720

30. Jiang B et al (2019) Microstructure and mechanical properties of TiB2-reinforced 7075 aluminum matrix composites fabricated by laser melting deposition. Ceram Int 45(5):5680-5692

31. Zhang J et al (2021) A novel crack-free Ti-modified Al-Cu-Mg alloy designed for selective laser melting. Additive Manuf 38:101829

32. Zhou SY et al (2020) Selective laser melting additive manufacturing of 7xxx series $\mathrm{Al}-\mathrm{Zn}-\mathrm{Mg}-\mathrm{Cu}$ alloy: Cracking elimination by co-incorporation of Si and TiB2. Additive Manuf 36:101458

33. Muddle BC, Polmear IJ (1989) The precipitate $\Omega$ phase in Al-CuMg-Ag alloys. Acta Metall 37(3):777-789

34. Ünal A (1990) Production of rapidly solidified aluminium alloy powders by gas atomisation and their applications. Powder Metall 33(1):53-64

35. International Alloy Designations and Chemical Composition Limits for Wrought Aluminum and Wrought Aluminum Alloys. 2015, The Aluminum Association

36. ASTM E8 / E8M-21, Standard Test Methods for Tension Testing of Metallic Materials. 2021, ASTM International, West Conshohocken, PA

37. 2021/01/01/; Available from: https://www.simufact.com/simufactadditive.html

38. Al-Obaisi AM et al (2017) Statistical model for the mechanical properties of Al-Cu-Mg-Ag alloys at high temperatures. Adv Mater Sci Eng 2017:1691465

39. https://www.simufact.com/material-data.html
40. Pandat_Database, Thermodynamic database for multi-component Aluminum-rich casting and wrought alloys, https://computherm. com/docs/pandat-database-manual/database-manual/panaluminum

41. Brice $\mathrm{C}$ et al (2015) Precipitation behavior of aluminum alloy 2139 fabricated using additive manufacturing. Mater Sci Eng, A 648:9-14

42. Brice CA et al (2018) Effect of compositional changes on microstructure in additively manufactured aluminum alloy 2139 . Mater Charact 143:50-58

43. Bhagavatam A et al (2018) Laser metal deposition of aluminum 7075 alloy. Int J Mater Sci Res 1:50-55

44. Yuan $\mathrm{T}$ et al (2020) Loss of elemental $\mathrm{Mg}$ during wire + arc additive manufacturing of $\mathrm{Al}-\mathrm{Mg}$ alloy and its effect on mechanical properties. J Manuf Process 49:456-462

45. Dai $\mathrm{D}$ et al (2017) Influence of additive multilayer feature on thermodynamics, stress and microstructure development during laser 3D printing of aluminum-based material. Sci Bull 62(11):779-787

46. Eskin DG, Suyinto, Katgerman L. Mechanical properties in the semi-solid state and hot tearing of aluminium alloys. Prog Mater Sci. 2004; 49:629-711

47. Kou S (2003) Solidification and liquation cracking issues in welding. JOM 55:37-42

48. Enz J et al (2016) Fibre laser welding of high-alloyed Al-Zn-Mg$\mathrm{Cu}$ alloys. J Mater Process Technol 237:155-162

49. Easton MA et al (2014) An a priori hot-tearing indicator applied to die-cast magnesium-rare earth alloys. Metall and Mater Trans A 45(8):3586-3595

50. Cheeseman BA, Gooch WA, Burkins MS. Ballistic evaluation of Aluminum 2139-T8. In: International symposium on ballistics. 2008. New Orleans, LA

51. Anderson K, Weritz J, Kaufman JG. 18.2.4 Heat Treatment, in ASM Handbook ${ }^{\circledR}$, Volume $2 \mathrm{~B}$ - properties and selection of aluminum alloys. ASM International

52. Belelli $\mathrm{F}$ et al (2021) Investigation on two Ti-B-reinforced $\mathrm{Al}$ alloys for laser powder bed fusion. Mater Sci Eng A 808:140944

53. Biffi CA et al (2021) Selective laser melting of AlCu-TiB2 alloy using pulsed wave laser emission mode: processability, microstructure and mechanical properties. Mater Des 204:109628

54. Kou S (2015) A criterion for cracking during solidification. Acta Mater 88:366-374

55. Rossenberg RA, Flemings MC, Taylor HF (1960) Nonferrous binary alloys hot tearing. AFS Trans 68:518-528

56. Stangeland A, Mo A, Eskin D (2006) Thermal strain in the mushy zone for aluminum alloys. Metall and Mater Trans A 37(7):2219-2229

57. Hagenlocher $\mathrm{C}$ et al (2018) Reduction of the hot cracking susceptibility of laser beam welds in AlMgSi alloys by increasing the number of grain boundaries. Sci Technol Weld Joining 24(4):313-319

58. Grandfield JF, Davidson CJ, Taylor JA (2000) The columnar to equiaxed transition in horizontal direct chill cast Magnesium Alloy AZ91. In: Ehrke K, Schneider W (eds) Continuous casting. WileyVCH Verlag GmbH \& Co. KGaA, pp 245-250

59. Warrington D, McCartney DG (1990) Hot-cracking in Aluminium Alloys 7050 and 7010-a comparative study. Cast Metals 3(4):202-208

60. Patel MN et al (2020) Understanding the refinement of grains in laser surface remelted Al-Cu alloys. Scripta Mater 178:447-451

61. Prasad A et al (2020) Towards understanding grain nucleation under additive manufacturing solidification conditions. Acta Mater 195:392-403 